Adams for access to a number of patients; Dr. J. Steel and Dr. J. C. Brundrett for facilities granted at Smithdown Road Hospital, Liverpool; the Medical Research Council for an expenses grant; and to the Medical Director-General of the Royal Navy for permission to publish data obtained at the Combined Services Hospital, Trincomalee, Ceylon.

REFERENCES

Acton, H. W. (1933). Trans. R. Soc. trop. Med. Hyg., 27, 119.

Adams, A. R. D. (1945). Ibid., 38, 237.

Fairbrother, R. W. (1944). British Medical Journal, 2, 489.

Faust, E. C., et al. (1939). J. Parasitol., 25, 241.

Hargreaves, W. H. (1946). Quart. J. Med., n.s. 15, 1.

Hurst, A. F. (1943). Medical Diseases of the War. Arnold, London.

Kershaw, W. E. (1946). British Medical Journal, 1, 305.

- O'Meara, P. J., and Stewart, G. T. (1948). Trans. R. Soc. trop. Med. Hyg., 41, 441.

Manson-Bahr, P. H. (1943). Dysenteric Disorders. Cassell, London.

O'Connor, R. J. (1947). Trans. R. Soc. trop. Med. Hyg., 41, 78.

Rogers, L. (1944). In Rogers and Megaw's Tropical Medicine Churchill, London.

Scadding, J. G. (1945). Lancet, 2, 549

Silverman, D. N., and Leslie, A. (1945). J. Amer. med. Ass., 129 187.

Stewart, G. T. (1947a). J. R. nav. med. Serv., 33, 6.

(1947b). Trans. R. Soc. trop. Med. Hyg., 41, 75

(1947c). J. Hyg., Camb., 45, 282.

(1948). Ann. trop. Med. Parasitol., 42, 198

and Jones, W. R. (1948). Ibid., 42, 33.

and Rogers, M. A.T. (1948). Nature, Lond. 161, 936.

$\bar{O}^{\prime}$ Meara, P. J., and Kershaw, W. E. (1948) J. $\ddot{R}$. nav. med Serv., 34, 2.

\section{PROGNOSIS IN BRONCHIAL ASTHMA}

BY

DERMOT MCCRACKEN, M.B., M.R.C.P.

Assistant Physician, Ashton-under-Lyne County Hośpital

Asthma was recognized before the time of the earliest medical literature, although it was only during the sixteenth century that bronchial asthma began to emerge as a distinct entity. Until this time other types of dyspnoea were confused with bronchial asthma, and indeed it took several centuries for the difference to be generally realized. Asthma was mentioned in the Ebers Papyrus, written 1,500 years B.c. (and so must have been known centuries before this), and in the writings of Homer and Herodotus. Hippocrates and Galen mention it, and Aretaeus of Cappadocia, a contemporary of Galen, gave the first fairly accurate description of an attack of asthma.

Until recent times few of the writers on asthma have made much mention of the prognosis. Henry Hyde Salter devoted the whole of Chapter 15 in his book on asthma, published in 1868 , to the prognosis. This, he said, depends on the duration of attacks (rather than their severity), their frequency, the completeness of recovery between them, their apparent tendency (that is, whether they appear to be getting more frequent and more severe, or less frequent and lighter), the length of time asthma has existed, the patient's age, and the presence or absence of organic mischief in heart and lungs. He thought that the prognosis in a patient under 15 years of age is almost invariably good, that there is no disease in which age is more important in the prognosis, and that the chances of recovery are in inverse proportion to the length of time the disease has existed.

After reading about asthma in the literature of all periods, what perhaps impresses one most is how some of the earlier physicians, by painstaking and detailed observation of patients, arrived at conclusions which we are to-day verifying and, indeed, in many cases rediscovering.

\section{Present Investigation}

An attempt has been made to analyse and assess the factors which govern the prognosis in bronchial asthma.
For this purpose patients who had been under observation for bronchial asthma for ten years or more were chosenpatients who made their first visit to the Cardiff Municipal Asthma Clinic in 1935 and 1936. This clinic is run in conjunction with the municipal hospital, to which doctors can refer any case of bronchial asthma or hay-fever living within the city boundaries. Approximately 200 to 400 new cases are seen each year. A team of doctors investigate the patients, treatment is instituted, and the patients are carefully followed up. The first 80 patients to attend in 1935 and 1,936 who could be traced and persuaded to attend for interview were seen personally between April, 1946, and April, 1947, when a detailed history was taken. Of the patients not included in the series the majority could not be traced, and most of the remainder had moved to distances precluding personal interview. In the case of patients who died, the relatives and the doctor attending the last illness were contacted. The cases were thus not selected in any way, and only those which appeared to be definite bronchial asthma were included in the series. A large number of patients whose asthma began in early life brought their parents with them to the interview, and the others had usually filled in any gaps in their own knowledge from their parents before coming.

To be accepted as a case of bronchial asthma a patient had to give a history of dyspnoea which occurred in or was much worse in paroxysms and was associated with a tight faeling in the chest. Patients who had had chronic bronchitis as babies and young children, and in whom paroxysmal dyspnoea developed later, were accepted, as were those in whom, following a typical earlier history, dyspnoea had become chronic, with merely fluctuations in its intensity. The asthma clinic records and any in-patient notes of the cases were consulted. The data obtained in this way were then analysed and an attempt made to assess the factors governing the prognosis in bronchial asthma.

In assessing the end-results the patients were placed in one of four categories-namely, cured, improved, unimproved, and dead. The total number of cases investigated was 80 , and the results were : cured, $17(21 \%)$ cases ; improved, 43 (54\%); unimproved, 12 (15\%); dead, 8 $(10 \%)$. It is of course difficult to speak of cure in asthma, as the patient may possibly develop symptoms again at some later period. The longer he is free, however, the less likely this is to occur, and the more justified we are in using the term "cure.". The criterion used in this investigation for placing the patient in the "cured" group is that no asthmatic symptoms whatever have been experienced for at least four to five years. Despite the stringent criteria for cure in the present series $21 \%$ have been "cured" for four to eleven years, and over $70 \%$ of this group for periods exceeding seven years (see Table I).

TABLE I.-Period of Freedom From Asthma in 17 Cured Cases

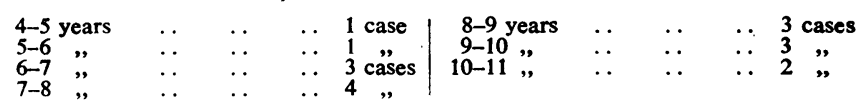

Cases in which a mild attack was experienced at intervals of years or in which occasional tightness of the chest was the only remaining manifestation-that is, cases in which "cure" seemed to have been almost but not quite achieved-were placed in the "improved" group, as were all cases showing any improvement occurring before and maintained up to the time of personal interview. Cases in which there was no improvement and those in which the condition was definitely worse were included in the unimproved group. The last group, of course, contains 
patients whose death was directly attributable to asthma and those in whom asthma bore no relation to the cause of death. An attempt has here been made to analyse and assess the factors which govern the prognosis.

\section{Influence of Age at Onset}

The age of the patient at the time of onset of the asthma seemed to play a part in the ultimate prognosis, as may be seen from Table II. From this it would seem

TABLE II.-Influence of Age at Onset upon Results

\begin{tabular}{|c|c|c|c|c|c|}
\hline Age at Onset & Cured & Improved & Unimproved & Dead & Total \\
\hline $\begin{array}{ccc}0-2 & \text { years } & \\
3-9 & \prime & \\
10-19 & \# & \\
20-29 & \# & \\
30+ & \# & . .\end{array}$ & $\begin{array}{l}8(29 \%) \\
6(26 \%) \\
1(11 \%) \\
1(9 \%) \\
1(11 \%)\end{array}$ & $\begin{array}{r}16(58 \%) \\
11(48 \%) \\
6(66 \%) \\
5(45 \%) \\
5(55 \%)\end{array}$ & $\begin{array}{l}2(7 \%) \\
5(22 \%) \\
1(11 \%) \\
3(27 \%) \\
1(11 \%)\end{array}$ & $\begin{array}{l}2(7 \%) \\
1(4 \%) \\
1(11 \%) \\
2(18 \%) \\
2(22 \%)\end{array}$ & $\begin{array}{r}28 \\
23 \\
9 \\
11 \\
9\end{array}$ \\
\hline
\end{tabular}

that the prognosis in the first two groups may be better than in the succeeding ones, but that the prognosis in the 0-2 group is not a great deal better than in the 3-9 group. The figures suggest that the prognosis may be improved in those cases in which asthma develops in the first decade. But it matters less whether it develops in the early or late part of the decade.

The ages of the 17 cured patients at the time of onset of their asthma was 0-9 years in 14 cases, 10-19 years in 1 case, 20-29 years in 1 case, 30 years and over in 1 case. Thus $82 \%$ of the cured cases developed asthma in their first decade (yet only $64 \%$ of cases in the series were in the $0-9$ age at onset group).

\section{Influence of Duration of Asthma before Attendance at the Clinic}

Many diseases are easier to treat in their earlier stages, and this might be expected to be particularly true in bronchial asthma, both because many people believe that there is a superimposed psychological factor in asthmatic attacks in many cases and because any disease affecting the respiratory tract is apt to produce permanent changes if long sustained. For this reason a note was made of the time elapsing between the onset of the patient's asthma and his attendance at the clinic, and also of the end-results, to see if the two were correlated.

TABLE' III.-Influence of Duration of Asthma Before Attendance at Clinic on Results Obtained in 49 Cases whose Asthma began at Ages 0-9

\begin{tabular}{|c|c|c|c|c|c|}
\hline $\begin{array}{c}\text { Duration } \\
\text { Before } \\
\text { Attendance }\end{array}$ & Cured & Improved & Unimproved & Dead & Total \\
\hline 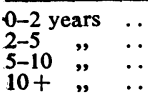 & $\begin{array}{l}2(40 \%) \\
7(58 \%) \\
3(18 \%) \\
2(13 \%)\end{array}$ & $\begin{array}{r}3(60 \%) \\
4(33 \%) \\
11(64 \%) \\
9(60 \%)\end{array}$ & $\begin{array}{l}0 \\
0 \\
2(12 \%) \\
3(20 \%)\end{array}$ & $\begin{array}{l}0 \\
1(9 \%) \\
1(6 \%) \\
1(7 \%)\end{array}$ & $\begin{array}{r}5 \\
12 \\
17 \\
15\end{array}$ \\
\hline
\end{tabular}

Table III shows these results in the 49 cases whose asthma began at ages 0-9 (inclusive) and who therefore have a uniformly good prognosis from the point of view of age of onset. With the exception of one of these patients who had received autogenous blood, and one who had been dieted by a herbalist, these 49 cases had received only symptomatic treatment from the family doctor before attendance at the clinic.

Table III suggests that early treatment is valuable in these cases. The prognosis in those cases seen within five years of onset may be better than that in those seen after :a longer delay.

\section{Influence of Sex}

Table IV shows the number of males and females developing asthma at different ages. This is shown graphically in the accompanying Chart.

TAble IV.-Age at Onset According to Sex

\begin{tabular}{ll|c|c|c|c}
\hline & \multicolumn{4}{|c}{ Age at Onset (Years) } \\
\cline { 3 - 6 } & & $0-9$ & $10-19$ & 20 and Over & Total \\
\hline Males & $\cdots$ & 30 & 4 & 10 & 44 \\
Females & $\cdots$ & 21 & 5 & 10 & 36 \\
\hline
\end{tabular}

As the prognosis is possibly better in those cases beginning in the first decade, and as males develop asthma at an earlier age than females, we should expect the prognosis to be better in males. The figures suggest that this is the case (see

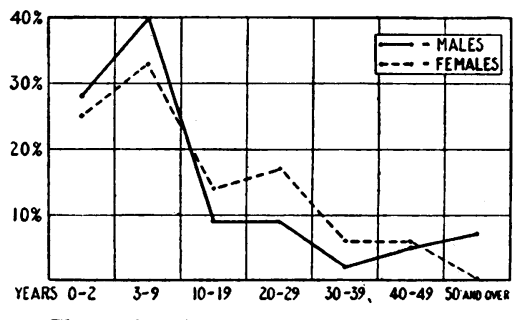

Chart showing percentage of cases falling into each age group (males and females).

Table V). The difference in results in the two sexes may not, however, be entirely due to the difference in the age at onset. Table VI shows the influence of sex upon the results in cases in which asthma began at age 0-9. The prognosis in males is still better than in females even when groups with a similar age of onset are compared.

TABLE V.-Influence of Sex upon Results

\begin{tabular}{ll|c|c|c|c|c}
\hline & & Cured & Improved & Unimproved & Dead & Total \\
\hline Males &. & $\begin{array}{c}10(23 \%) \\
\text { Females }\end{array}$ & $\begin{array}{c}26(59 \%) \\
\text { (19\%) }\end{array}$ & $\begin{array}{c}\mathbf{1 7}(47 \%) \\
8(22 \%)\end{array}$ & $\begin{array}{c}4(9 \%) \\
\mathbf{4}(11 \%)\end{array}$ & $\begin{array}{l}44 \\
36\end{array}$ \\
\hline
\end{tabular}

TABLE VI.-Influence of Sex Upon Results in Cases in which Asthma Began at Ages 0-9

\begin{tabular}{|c|c|c|c|c|c|c|}
\hline & & Cured & Improved & Unimproved & Dead & Total \\
\hline $\begin{array}{l}\text { Males } \\
\text { Females }\end{array}$ & .. & $\begin{array}{l}9(30 \%) \\
5(24 \%)\end{array}$ & $\begin{array}{r}18(60 \%) \\
9(43 \%)\end{array}$ & $\begin{array}{l}3(10 \%) \\
4(19 \%)\end{array}$ & $3(14 \%)$ & $\begin{array}{l}30 \\
21\end{array}$ \\
\hline
\end{tabular}

\section{Chronic Respiratory Symptoms}

Certain sufferers from bronchial asthma develop chronic respiratory symptoms which are persistently present in between their attacks of asthma. In this investigation patients who suffered from cough or sputum or shortness of breath between their attacks were considered to be suffering from chronic respiratory symptoms, while those who were quite free from such symptoms except during the actual asthmatical attacks were considered not to be suffering from chronic respiratory symptoms (their incidence in short-term infections was ignored) : $16(22 \%)$ suffered from chronic respiratory symptoms and $58(78 \%)$ did not.

In an effort to ascertain the factors responsible for cases developing chronic respiratory symptoms a table was worked out to show the age of onset of those developing them and the age of onset of those not developing them (Table VII). Thus of those cases developing chronic

TABLE VII

\begin{tabular}{|c|c|c|c|c|}
\hline \multicolumn{3}{|c|}{ Age at Onset } & $\begin{array}{l}\text { Cases with Chronic } \\
\text { Respiratory Symptoms }\end{array}$ & $\begin{array}{l}\text { Cases without Chronic } \\
\text { Respiratory Symptoms }\end{array}$ \\
\hline $\begin{array}{l}0-9 \text { years } \\
10-19, " \\
20-29 " \\
30 \text { and over . }\end{array}$ & $\begin{array}{l}\ddot{*} \\
\ddot{\ldots}\end{array}$ & $\begin{array}{l}\ddot{ } \\
\ddot{*}\end{array}$ & $\begin{array}{l}8(50 \%) \\
3(17 \%) \\
2(12 \%) \\
3(17 \%)\end{array}$ & $\begin{array}{l}36(62 \%) \\
9(16 \%) \\
9(16 \%) \\
4(7 \%)\end{array}$ \\
\hline
\end{tabular}


respiratory symptoms a smaller percentage fall into the youngest age group than into the older groups.

Of those patients who came for treatment relatively late after the onset of symptoms a greater percentage develop chronic respiratory symptoms (Table VIII). Patients

TABLE VIII.-Influence of "Duration of Asthma Before Attendance at Clinic" on Incidence of Chronic Respiratory Symptoms

\begin{tabular}{|c|c|c|c|c|}
\hline \multicolumn{3}{|c|}{$\begin{array}{l}\text { Duration of Asthma Before } \\
\text { Attendance at Clinic }\end{array}$} & \multirow{2}{*}{$\begin{array}{c}\begin{array}{c}\text { Cases with Chronic } \\
\text { Respiratory Symptoms }\end{array} \\
2(13 \%) \\
4(25 \%) \\
5(31 \%) \\
5(31 \%)\end{array}$} & \multirow{2}{*}{ 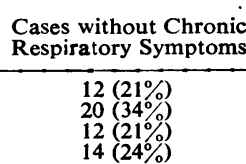 } \\
\hline $\begin{array}{l}0-2 \text { years } \\
2-5 \quad " \\
5-10 \quad " \\
10+\quad ",\end{array}$ & $\begin{array}{l}\ldots \\
\cdots \\
\ldots\end{array}$ & $\begin{array}{l}\cdots \\
\cdots \\
\cdots\end{array}$ & & \\
\hline
\end{tabular}

should therefore be encouraged to report for advice and treatment as soon as possible after developing symptoms of bronchial asthma for two reasons : the chance of cure is greater if they do so, and the incidence of chronic respiratory symptoms is less among such patients.

\section{Types of Allergen}

Over $50 \%$ of cases were found to be sensitive to multiple allergens, and the prognosis in these cases was very much poorer than in those in which only one allergen could be found (Table IX). On the other hand, those sensitive

TABLE IX

\begin{tabular}{c|c|c|c|c|c}
\hline Allergen & Cured & Improved & Unimproved & Dead & Total \\
\hline $\begin{array}{c}\text { Multiple . } \\
\text { House-dust }\end{array}$ & $7 \%$ & $56 \%$ & $20 \%$ & $17 \%$ & 41 \\
$\begin{array}{c}\text { and feathers } \\
\text { Not known. }\end{array}$ & $33 \%$ & $66 \%$ & 0 & 0 & 12 \\
\hline Whole series & $21 \%$ & $53 \%$ & $11 \%$ & 0 & 19 \\
\hline
\end{tabular}

to house-dust and feathers have a better prognosis. The members of this group are fortunate in that they can undergo a course of desensitization and avoid feathers. Other workers have noted particularly good results in asthma due to pollen, and it seems that considerable help can be given to patients whose asthma is due to inhalants.

\section{Other Allergic Conditions}

An attempt was made in all cases to find out from the patients or their relatives whether there was a personal and/or family history of allergic manifestations other than asthma. The conditions regarded as being allergic manifestations for the purpose of this investigation were : migraine, urticaria, hay-fever, vasomotor rhinitis, gastrointestinal allergic manifestations, and infantile eczema. It was found that 57 cases $(72 \%)$ gave a personal history of one or more of these conditions, while 22 cases $(28 \%)$ did not. Of the 57 patients who gave a personal history of such conditions 23 suffered from one other manifestation, 24 from two other manifestations, 5 from three, 2 from four, 2 from five, and 1 from six. Thus 47 out of these 57 suffered, in addition to asthma, from two other diseases which were probably allergic in origin.

Table $X$ shows how the prognosis is affected when patients have a personal history of one or more of these other conditions. The prognosis appears to be very much better in those cases in which asthma is the only allergic

\begin{tabular}{|c|c|c|c|c|c|}
\hline & Cured & Improved & Unimproved & Dead & Total \\
\hline \multirow{2}{*}{$\begin{array}{c}\text { Personal his- } \\
\text { tory } \\
\text { No personal } \\
\text { history ... }\end{array}$} & $18 \%$ & $54 \%$ & $19 \%$ & $9 \%$ & 57 \\
\hline & $32 \%$ & $55 \%$ & $5 \%$ & $9 \%$ & 22 \\
\hline
\end{tabular}

manifestation. The relation of a personal history of other allergic conditions to the age at onset was investigated. It was found to have had no effect in the present series, and the prognosis is therefore affected in some other way.

\section{Family History}

In the 78 cases in which the family history could be clearly ascertained it was found that 42 had no history of asthma on either side, 33 gave a history of asthma on one side or the other (16 paternal, 17 maternal), and 3 a history of asthma on both sides. It therefore seems that there is no sex difference in the transmission of asthma.

The effect of allergic manifestations, including asthma, upon the prognosis would be greater than the effect of asthma alone. Investigation was made into the effect upon the prognosis of a family history in any generation (including siblings) of asthma or any of the six allergic manifestations listed; in this series no effect was shown. It was also found that a family history of allergy had no bearing upon the age at onset. It was found that 59 cases $(77 \%)$ have a positive history and only $18(23 \%)$ a negative one. It would be interesting to know how many of the $23 \%$ have a family history of allergic manifestations unknown to them. It is reasonable to assume that some have such a history, and if the number should prove to be considerable it would mean that most families have some members with allergic manifestations.

Skin Reactions.-The presence or absence of positive reactions was not found to affect the prognosis.

\section{Size of Family and Age of Parents}

Table XI shows the effect upon the patient's prognosis of the number of brothers and sisters. In the fatal cases the size of family was not ascertained.' With the exception

TABLE XI.-Effect of Size of Family upon Prognosis in 70 Cases

\begin{tabular}{|c|c|c|c|c|c|}
\hline $\begin{array}{c}\text { No. of } \\
\text { Children } \\
\text { in Family }\end{array}$ & Cured & Improved & Unimproved & Dead & Total \\
\hline 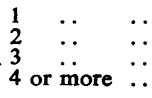 & $\begin{array}{l}17 \% \\
36 \% \\
18 \% \\
21 \%\end{array}$ & $\begin{array}{l}83 \% \\
57 \% \\
69 \% \\
56 \%\end{array}$ & $\begin{array}{l}\overline{7 \%} \\
13 \% \\
24 \%\end{array}$ & $\bar{z}$ & $\begin{array}{r}6 \\
14 \\
16 \\
34\end{array}$ \\
\hline
\end{tabular}

of the figure $17 \%$ in the "cured" column for "only" children the prognosis appears better the smaller the family. This particular figure can perhaps be explained by the fact that parents of "only" children tend to be over-anxious about them, this atmosphere being felt by the child and leading to an environment unfavourable for cure.

TABlE XII.-Age of Parents in 68 Cases

\begin{tabular}{|c|c|c|c|c|c|}
\hline $\begin{array}{c}\text { Average Age } \\
\text { of Parents }\end{array}$ & Cured & Improved & Unimproved & Dead & Total \\
\hline $\begin{array}{l}\text { Up to and in- } \\
\text { cluding } 25 \\
26-30 \\
31-35 \\
35+\end{array}$ & $\begin{array}{l}16 \% \\
26 \% \\
24 \% \\
33 \%\end{array}$ & $\begin{array}{l}74 \% \\
52 \% \\
53 \% \\
67 \%\end{array}$ & $\begin{array}{l}10 \% \\
22 \% \\
24 \% \\
\end{array}$ & 二 & $\begin{array}{r}19 \\
23 \\
17 \\
9\end{array}$ \\
\hline
\end{tabular}

Table XII shows the effect of the average age of the parents at the time of the patient's birth. It seems that on the whole the prognosis is better where the parents are older, but this result may be fortuitous. On the other hand, the social and economic status tends to be better in the older parental group, and the results here might also be correlated with the results of Table XI-that the results are poorer, or at least the percentage of cases not improved is greater, in the bigger families. 


\section{Effects of Menstruation and Pregnancy}

The effect of menstruation upon asthma in 30 female patients was : no effect in 20 cases $(66.6 \%)$ and worse in 10 cases $(33.3 \%)$. The effect of pregnancy in 9 patients was : better in $5(56 \%)$, no effect in $2(22 \%)$, and worse in $2(22 \%)$. Of the five who were better during pregnancy, three were among those whose asthma was not affected by menstruation and two among those whose asthma was worse during their periods.

The results in the 10 cases that were worse during menstruation are exceedingly poor compared with the series as a whole. They were : cured, $10 \%$; improved, $40 \%$; and unimproved, $50 \%$.

\section{Operations upon the Upper Respiratory Tract}

Twenty-two patients underwent operations upon polypi, sinuses, tonsils, adenoids, and/or nasal septa subsequent to the development of asthma, and remembered the results of such operations upon their asthma. There was no effect in 16, one case experienced temporary.improvement, and five cases were permanently improved. All the six patients who improved had had operations upon polypi, sinuses, and/or septa, and none upon tonsils and adenoids. It also seems worthy of comment that in most of the relieved cases the relief was permanent.

\section{Death in Bronchial Asthma}

In the series of 80 cases there were eight deaths-in four asthma was the main or sole cause of death, but in four it bore no relation to death. The data concerning the four cases whose death was directly due to asthma are given in Table XIII.

TABLE XIII.-Data Concerning Cases in which Death was Directly and Solely Due to Asthma

\begin{tabular}{|c|c|c|c|c|}
\hline & Case 1 & Case 2 & Case 3 & Case 4 \\
\hline 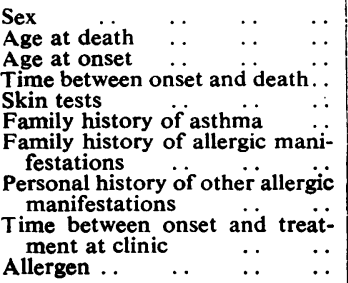 & $\begin{array}{l}\text { Male } \\
47 \text { years } \\
29 ", \\
18 \text { " } \\
\text { Negative } \\
\text { Yes } \\
\text { Yes } \\
\text { Yes } \\
13 \text { years } \\
\text { Multiple }\end{array}$ & $\begin{array}{l}\text { Female } \\
13 \frac{1}{2} \text { years } \\
22 \frac{1}{2}, " \\
11 \text { " } \\
\text { Positive } \\
\text { Yes } \\
\text { Yes } \\
\text { Yes } \\
8 \text { years } \\
\text { Multiple }\end{array}$ & \begin{tabular}{|l|} 
Male \\
50 years \\
19 " \\
Positive \\
Yes \\
Yes \\
Not known \\
28 years \\
Multiple
\end{tabular} & $\begin{array}{l}\text { Female } \\
17 \text { years } \\
7 \% ", \\
10 \text { ", } \\
\text { Positive } \\
\text { No } \\
\text { Yes } \\
\text { Yes } \\
2 \text { years } \\
\text { Multiple }\end{array}$ \\
\hline
\end{tabular}

It will be noted from the table that there were present a personal history of other allergic manifestations in the three cases in which this part of the history could be ascertained, a family history of allergic manifestations in all four cases, and a family history of asthma in three. Three of the four cases had experienced asthma for many years before seeking treatment. Three of the four cases gave positive skin reactions, and all four were sensitive to multiple allergens.

\section{Conclusion}

If the findings in this investigation are confirmed by others it means that we have enough data in our possession to enable us, in a large number of cases, to give some idea of the prognosis, and in some cases to forecast it with accuracy. It is realized that a larger series of cases would have borne more weight, but the amount of clerical work involved and the absence of clerical assistance, "together with the difficulty in contacting cases after such a long period of time, precluded this. However, it is hoped that the results are suggestive enough to stimulate further investigations along lines not previously explored, as so far there seem to be no figures available for comparison with many of those given here.

I am indebted to Dr. D. G. Morgan for access to the cases and records of the Cardiff Municipal Asthma Clinic, and to Professor A. M. Kennedy, director of the Medical Unit of the Welsh National School of Medicine, and Dr. D. A. Williams, physician in charge of the asthma clinic, for much helpful advice and criticism.

\section{LOW SPINAL ANALGESIA IN OPERATIVE OBSTETRICS \\ A FURTHER SERIES OF 511 CASES}

BY

\section{E. E. RAWLINGS, M.D., M.R.C.O.G. \\ Obstetrician and Gynaecologist, Hope Hospital, Salford}

Spinal analgesia has been a method of choice in the obstetrical and gynaecological departments of Hope Hospital for the past six years. During this time it has been used for 1,130 major gynaecological operations, 287 caesarean sections, and 767 operative vaginal deliveries, making a total of 2,184 cases, and has proved eminently satisfactory.

It is not my intention to add fuel to the already burning question of spinal analgesia for caesarean section. This topic has been fully dealt with by Thomas (1942, 1944), Resnick (1945), and others. Most of the arguments used against it can easily be refuted by the wealth of evidence in its favour. However, these arguments have even less bearing on the question of low spinal analgesia in operative vaginal deliveries. Resnick published a full analysis of 394 cases of heavy cinchocaine hydrochloride ("nupercaine") analgesia in operative obstetrics-138 caesarean sections and 256 operative vaginal deliveries. These were performed at Hope Hospital over a two-year period ending August, 1945.

This paper reviews a further series of operative vaginal deliveries under spinal analgesia and assesses the safety and suitability of this analgesic in obstetric practice. The 511 cases analysed below are in addition to the 256 cases presented by Resnick, and were performed during the period August, 1945, to May, 1949.

\section{Technique}

Ephedrine, 1 gr. (65 mg.), was given intramuscularly half an hour before the operation when time permitted. In recent years this has been dispensed with in the majority of cases without any adverse effect. The preparation used throughout has been heavy cinchocaine (" nupercaine 1 in 200 in $6 \%$ glucose). Low forceps deliveries have been done with as little as $0.5 \mathrm{ml}$. (2.5 mg.), but on an average $0.7 \mathrm{ml}$. (3.5 mg.) has been administered. The technique followed is that used by Resnick (1945), with the following modifications. Barbotage was not employed, and the needle was inserted between the third and fourth lumbar vertebrae with the patient in the sitting position. A fine needle, 20-22 s.w.G. (0.9-0.7 mm.), short bevel, rustless steel, was used.

\section{Analysis of the Cases}

Spinal analgesia was employed for all deliveries except in cases of severe haemorrhage, internal version, and eclampsia. In connexion with the latter, Anderson (1946) and Cosgrove (1927) consider spinal analgesia to be eminently satisfactory. I have no experience of its use in this condition. In patients with heart disease, if a midforceps delivery was indicated, spinal analgesia was used in preference to a pudendal block. 